\title{
How should addiction-related research at the National Institutes of Health be reorganized?
}

\section{Bankole A. Johnson ${ }^{*}$, Robert O. Messing ${ }^{2}$, Michael E. Charness ${ }^{3}$, John C. Crabbe ${ }^{4}$, Mark S. Goldman ${ }^{5}$, R. Adron Harris ${ }^{6}$, Henry R. Kranzler ${ }^{7}$, Mack C. Mitchell Jr. ${ }^{8}$, Sara Jo Nixon ${ }^{9}$, Edward P. Riley ${ }^{10}$, Marc A. Schuckit ${ }^{11}$, Kenneth J. Sher ${ }^{12}$ and Jennifer D. Thomas ${ }^{10}$}

\author{
1 Department of Psychiatry and Neurobehavioral Sciences, University of Virginia, Charlottesville, VA, USA \\ 2 Ernest Gallo Clinic and Research Center, Department of Neurology, University of California, San Francisco, San Francisco, CA, USA \\ 3 VA Boston Healthcare System, Department of Neurology, Harvard Medical School, Boston University School of Medicine, Boston, MA, USA \\ 4 Portland Alcohol Research Center, Department of Behavioral Neuroscience, Oregon Health \& Science University and VA Medical Center, Portland, OR, USA \\ ${ }_{5}$ Alcohol \& Substance Use Research Institute, Department of Psychology, University of South Florida, Tampa, FL, USA \\ ${ }^{6}$ Section of Neurobiology, School of Biological Sciences, Waggoner Center for Alcohol and Addiction Research, University of Texas at Austin, Austin, TX, USA \\ 7 Department of Psychiatry, Treatment Research Center, University of Pennsylvania, Philadelphia, PA, USA \\ ${ }^{8}$ Department of Internal Medicine, Johns Hopkins University School of Medicine, Johns Hopkins Bayview Medical Center, Baltimore, MD, USA \\ ${ }^{9}$ Division of Addiction Research, Department of Psychiatry, University of Florida, Gainesville, FL, USA \\ ${ }^{10}$ Department of Psychology, Center for Behavioral Teratology, San Diego State University, San Diego, CA, USA \\ "Department of Psychiatry, University of California, San Diego, La Jolla, CA, USA \\ ${ }^{12}$ Department of Psychological Sciences, University of Missouri-Columbia, and Midwest Alcoholism Research Center, Columbia, MO, USA \\ ${ }^{*}$ Correspondence: bankolejohnson@virginia.edu
}

The decades-old debate about the optimum organizational structure of the National Institute on Alcohol Abuse and Alcoholism (NIAAA) and National Institute on Drug Abuse (NIDA) has reached a crescendo with the recent deliberations of the Scientific Management Review Board, which, despite the lack of a crisis, proposed a structural reorganization that would dissolve the two institutes and create a new institute for substance use, abuse, and addiction, in hope of new scientific and public health advances (Collins, 2010). For a new institute to succeed, a multitude of potential challenges need to be negotiated effectively.

Notably, new funds will be needed, even in the current difficult national economic climate, to coalesce the infrastructure of NIAAA and NIDA and incorporate addiction-related research currently conducted by other National Institutes of Health (NIH) institutes. To succeed, the new institute would also require an enormous amount of cooperation from other institutes as the portfolios of research in the areas of alcohol, tobacco, and other drug abuse are transferred to it. Thus, in the near term, a structural reorganization would be less efficient and more costly than the individual institutes are currently. Only with careful strategic planning would it be possible to increase efficiency and reduce costs over time.

If the process moves forward smoothly, Dr. Francis Collins, NIH Director, has proposed launching the new entity by October 2012. However, if reorganization is to be unveiled slowly and progressively over the next 2 years with gradual integration of two disparate cultures, another approach could be to intensify and strengthen current collaborations through an NIAAA-NIDA Joint Task Force. The NIH Director could determine a specific percentage of resources from each institute to be committed for collaborative research agendas modeled on the same governance and operational structures currently used by the Neuroscience Blueprint and the Basic Behavioral Research Operations Network. In this way, a clearer road map could be developed that provides for due diligence and critical information gathering to understand the practical needs and challenges of developing an informed organizational approach. Predetermined milestones can be used to evaluate progress and adjust course as needed to ensure a viable plan that incorporates all relevant research.

Importantly, although there are common mechanisms mediating the rewarding effects of alcohol and other drugs, distinctions also exist. For example, there is considerable evidence that substances of abuse express their addictive potential, in part, through similar brain circuits, most notably the cortico-mesolimbic dopamine circuit (Johnson, 2010). Nevertheless, despite decades of research, the approach of direct antagonism of cortico-mesolimbic dopamine receptors has not yet yielded efficacious medicines to treat addiction. In fact, pharmacological differences between alcohol and other drugs might hold the key to successful medications development for these different disorders. Thus, rather than focusing on a narrow conceptualization of the addiction circuitry, the new institute should seek diligently to understand how diverse and complex mechanisms contribute to abuse of alcohol and other substances.

Nutt et al. (2010) noted that in the United Kingdom, the overall harm to both the individual and others was greatest for alcohol. Alcohol is the addictive substance that is most commonly used by the United States population, with a prevalence of about 65.4\% (Table 1; Grant et al., 2011). Addiction to alcohol is, however, far less common, as a proportion of its use, than addiction to many other drugs of abuse. Nonetheless, Rehm et al. (2009) found that the total economic cost of alcohol abuse in the United States in 1998 was nearly \$235 billion (adjusted to 2007 international dollars). The harm to society attributed to alcohol consumption often results from alcohol use disorders that include the inappropriate use of alcohol in situations such as before driving or by underage drinkers, rather than addiction to alcohol. A 2010 fact sheet from the Centers for Disease Control and Prevention reports that during 2000-2004, annual health-related economic losses in the United States due to cigarette smoking were estimated at $\$ 193$ billion ( $\$ 96$ billion in direct medical costs plus $\$ 97$ billion in lost productivity). Data from the Office of National Drug Control Policy in 2002 showed that the total economic impact in the United States of all illicit drugs combined was about $\$ 200$ billion, but $60 \%$ of that amount was related to incarceration. 
Table 1 | Past-year liability for various types of substance dependence, based on 200 million United States adults $\geq 18$ years of age (2001-2002).

\begin{tabular}{lcccc}
\hline & $\begin{array}{l}\text { Prevalence (\%) } \\
\text { of past-year use }\end{array}$ & $\begin{array}{l}\text { Number of individuals } \\
\text { with past-year use }\end{array}$ & $\begin{array}{l}\text { Percentage of past-year } \\
\text { users with past-year dependence }\end{array}$ & $\begin{array}{l}\text { Number of individuals } \\
\text { with past-year dependence }\end{array}$ \\
\hline Alcohol & 65.44 & $130,880,000$ & 5.82 & $7,617,216$ \\
Tobacco & 27.66 & $55,320,000$ & 46.13 & $25,519,116$ \\
Sedatives & 1.24 & $2,480,000$ & 5.42 & 134,416 \\
Tranquilizers & 0.93 & $1,860,000$ & 5.04 & 93,744 \\
Painkillers & 1.81 & $3,620,000$ & 6.3 & 228,060 \\
Stimulants & 0.49 & 980,000 & 14.34 & 140,532 \\
Marijuana & 4.07 & $8,140,000$ & 7.96 & 647,944 \\
Cocaine/crack & 0.56 & $1,120,000$ & 23.91 & 267,792 \\
Hallucinogens & 0.57 & $1,140,000$ & 2.67 & 30,438 \\
Solvents/inhalants & 0.11 & 220,000 & 1.04 & 2,288 \\
Heroin & 0.03 & 60,000 & 26.96 & 16,176 \\
\hline
\end{tabular}

The data in this table are from Wave I of the National Epidemiologic Survey on Alcohol and Related Conditions (2001-2002; Grant et al., 2011).

Hence, the new institute should focus on (1) alcohol use disorders, including alcoholism, (2) tobacco addiction, and (3) illicit drug addictions as a group, in that order.

Careful thought is needed to determine the programmatic components of the new institute. Fragmentation or segregation of ongoing programs such as those involving fetal alcohol spectrum disorders, alcoholic liver disease, or prevention and treatment does not serve the public good and must be avoided. Tobacco research should be a major focus of a new institute and not the sole purview of the National Cancer Institute (NCI) or National Heart, Lung and Blood Institute (NHLBI) so that the prevention and treatment of tobacco addiction is not subsumed by the study of its general health consequences. Indeed, tobacco is, by far, the most addictive of all the drugs (Table 1), followed by heroin and crack cocaine (percentage of pastyear users with past-year dependence; Grant et al., 2011). It would certainly be unreasonable to expect scientists within NCI and NHLBI to be experts on addiction, and for many, such specialist training would be lacking. Comorbid alcohol and drug addiction is at the interface of a collaborative scientific enterprise and, in the future, should receive appropriate funding and opportunities for development. Because of the strong interrelationship between alcohol and tobacco use, abuse, and addiction, a new institute would not be well grounded if it did not incorporate both. It is intriguing to consider whether parts of the National Institute of Mental
Health should also be included within this new institute to address prevention and treatment of comorbid substance use disorder and mental illness, as well as some behavioral addictive disorders.

These deliberations have identified an opportunity to increase collaboration and broaden the thinking and vision of scientists to promote public health. If a new institute for substance use, abuse, and addiction is established, new leadership that is credible and respected by both the alcohol and drug addiction communities is needed to drive the new institute, inspire new vistas, build more intensive collaborations, and motivate staff to do what they have always done best - serve the public good. Otherwise, the path toward a structural reorganization of a new institute that meets some of the promise proposed for it, even with careful and strategic planning, could become a famished road (Okri, 1992) that simply consumes people and resources with no tangible gains. Success in this difficult task would be made easier and less costly by first implementing carefully placed building blocks of increasing functional reorganization. Indeed, for the structural reorganization of a new institute to succeed, attention needs to be paid to the devil in the details.

\section{ACKNOWLEDGMENTS}

We are grateful to John Wiley \& Sons, Inc., for permission to reproduce some text from our recent commentary (Johnson et al., 2011). We also thank Robert H. Cormier Jr., BA, and Ann Richards, BA, for their assistance with manuscript preparation.

\section{DISCLOSURES}

B. A. Johnson has served as a consultant to Johnson \& Johnson (Ortho-McNeil Janssen Scientific Affairs, LLC), Transcept Pharmaceuticals, Inc., D\&A Pharma, Organon, ADial Pharmaceuticals LLC, Psychological Education Publishing Company (PEPCo LLC), and Eli Lilly and Company. He also has served on the Extramural Advisory Board for NIAAA (2004-present), the National Advisory Council for NIDA (2004-2007), the Medications Development Subcommittee of NIDA's Advisory Council on Drug Abuse (2004-2007), and the Medications Development Scientific Advisory Board for NIDA (2005-2009). In addition, he has been the recipient of research grant support from both NIAAA and NIDA. R. O. Messing has served on the Board of Scientific Counselors for NIAAA (20022008) and on the Medical Advisory Council of ABMRF, The Foundation for Alcohol Research (2006-2009), and has been the recipient of research grant support from NIAAA. M. E. Charness is on the Scientific Advisory Board of Allon Therapeutics. H. R. Kranzler has been a paid consultant for Alkermes, Inc., GlaxoSmithKline, and Gilead. He has received research support from Merck. He also reports associations with Eli Lilly and Company, Janssen, Schering Plough, Lundbeck, Alkermes, Inc., GlaxoSmithKline, Abbott, and Johnson \& Johnson, as these companies provide support to the ACNP Alcohol Clinical Trials Initiative (ACTIVE) and Dr. Kranzler receives support from ACTIVE. M. C. 
Mitchell is the President of ABMRF, The Foundation for Alcohol Research, and is a consultant for Alkermes, Inc. and Orexigen. K. J. Sher has served as a consultant to the Joint Defense Group, a group of law firms representing various major brewers on a then-pending class action lawsuit (2006-2007). He also has served on the Psychosocial Advisory Council for the Alcoholic Beverage Medical Research Foundation (1992-1998; 2001-2007), the Extramural Advisory Board for NIAAA (1991-1992; 2004-2007; 2009-present), the National Advisory Council on Alcohol Abuse and Alcoholism (2003-2007), and various ad hoc task forces and working groups for NIAAA. In addition, he has been the recipient of research grant support from NIAAA. J. C. Crabbe, M. S. Goldman, R. A. Harris, S. J. Nixon, E. P. Riley, M.A. Schuckit, and J. D. Thomas have no financial disclosures or conflicts of interest to report.

\section{REFERENCES}

Collins, F. S. (2010). Statement of NIH Director Francis S. Collins, M.D., Ph.D., on recommendation to create a single institute for substance use, abuse, and addiction research. http://www.nih.gov/news/ health/nov2010/od-18.htm. NIH News, November $18,2010$.

Grant, B. F., Dawson, D. A., and Moss, H. B. (2011). Disaggregating the burden of substance dependence in the United States. Alcohol. Clin. Exp. Res. 35, 387-388.

Johnson, B. A. (2010). "Opportunities, challenges, and successes in the development of medicines for the treatment of addiction," in Addiction Medicine: Science and Practice, ed. B. A. Johnson (New York: Springer Science + Business Media), 1525-1537.

Johnson, B. A., Messing, R. O., Charness, M. E., Crabbe, J. C., Goldman, M. S., Harris, R. A., Kranzler, H. R., Mitchell, M. C. Jr., Nixon, S. J., Riley, E. P., Schuckit, M. A., Sher, K. J., and Thomas, J. D. (2011). Should the reorganization of addiction-related research across all the National Institutes of Health be structural? - The devil is truly in the details. Alcohol. Clin. Exp. Res. $35,572-580$.

Nutt, D. J., King, L.A., Phillips, L. D., and the Independent Scientific Committee on Drugs (2010). Drug harms in the UK: a multicriteria decision analysis. Lancet 376, 1558-1565.

Okri, B. (1992). The Famished Road. New York: Nan A. Talese/Doubleday.

Rehm, J., Mathers, C., Popova, S., Thavorncharoensap, M., Teerawattananon, Y., and Patra, J. (2009). Global burden of disease and injury and economic cost attributable to alcohol use and alcohol-use disorders. Lancet $373,2223-2233$.

Received: 15 February 2011; accepted: 15 February 2011; published online: 03 May 2011.

Citation: Johnson BA, Messing RO, Charness ME, Crabbe JC, Goldman MS, Harris RA, Kranzler HR, Mitchell MC Jr., Nixon SJ, Riley EP, Schuckit MA, Sher KJ and Thomas JD (2011) How should addiction-related research at the National Institutes of Health be reorganized? Front. Psychiatry 2:2. doi: 10.3389/fpsyt.2011.00002

This article was submitted to Frontiers in Addictive Disorders, a specialty of Frontiers in Psychiatry.

Copyright $\odot 2011$ Johnson, Messing, Charness, Crabbe, Goldman, Harris, Kranzler, Mitchell, Nixon, Riley, Schuckit, Sher and Thomas. This is an open-access article subject to a non-exclusive license between the authors and Frontiers Media SA, which permits use, distribution and reproduction in other forums, provided the original authors and source are credited and other Frontiers conditions are complied with. 